\title{
Há luz aqui, confissões ${ }^{1}$
}

\section{There is light here, confessions}

Nara Waldemar Keiserman ${ }^{2}$ 


\section{Resumo}

O artigo apresenta, em tom confessional, questões relativas aos temas Teatro e Espiritualidade e Teatro e Ritual, conforme vêm sendo experimentadas e discutidas no âmbito da pesquisa Ator rapsodo: pesquisa de procedimentos para uma linguagem gestual, coordenada pela autora e desenvolvida na Escola de Teatro da Unirio, com apoio do Grupo de Pesquisa Artes do Movimento. A escrita apresenta afinidades com a ideia de "desmontagem" (Diéguez, 2009), em que aspectos subjetivos do artista cênico criador são eventualmente revelados.

Palavras-Chave: Teatro e Espiritualidade; Teatro e Ritual; Atuação Cênica; Teatro Rapsódico; Ator Narrador

\section{Abstract}

The article presents, in a confessional way, issues related to the themes Theatre and Spirituality and Theatre and Ritual, as have been experienced and discussed in the research Actor rhapsode: research procedures to gestual language, coordinated by the author and developed at the Theatre School of Unirio, with support of Research Group Movement Arts. The writing is connected with the idea of "disassembly" (Diéguez, 2009), where subjective aspects of the artist scenic creator are eventually revealed.

Keywords: Theater and Spirituality; Theatre and Ritual; Scenic Acting; Rhapsodic Theater; Actor Rhapsodist 


\section{Introdução}

Escrevo para os que acreditam, como eu, no que veem e no que não veem, numa escala infinita de invisibilidades. Não se trata de tornar visível o invisível e sim de manter a invisibilidade e entrar em contato com ela através de todos os nossos corpos, alguns também invisíveis. Não escrevo para persuadir ou convencer, mas para partilhar, confessar, depor, desabafar. É neste tom que se dá a escrita que segue.

Venho partilhar minhas dúvidas e pensamentos conectados com a vivência atual nas esferas da Cena, em que tenho estado como atriz, e da Sala de Trabalho (professora e também orientadora de uma pesquisa institucional, numa etapa que chamei, desde 2012, de Teatro e Espiritualidade), e que estão totalmente amalgamadas.

Inicio confessando que tenho dois vícios: 1) acredito em tudo o que leio e por isso, ultimamente, só leio sobre aquilo em que acredito; 2) tudo o que leio, considero a possibilidade de encenar. Estes dois vícios apontam para algumas especificidades investigativas: há um sistema de crenças que sustenta a cena e tudo o que ela abarca; e uma aposta no texto não dramatúrgico como componente literário da criação.

Como um desabafo, venho partilhar que não sou conhecedora das filosofias, o que me põe em risco de contradições. Não me importo. Quando um amigo sábio recomendou que eu ficasse atenta para que minha pesquisa se mantivesse científica, tive certeza de que isso ela não é. Compreendo o ponto de vista do meu amigo. Ateu, sua observação se deu quando passei a assumir uma espiritualidade na pedagogia e na cena que pratico. Mas a sacralidade que pretendo ostentar tem muito pouco ou nada a ver com Deus, propriamente, mas sim com uma visão cósmica do Universo e a crença na sua perfeição e harmonia. Para entender um sentido de harmonia maior do que o do cotidiano ou mesmo aquele que aponta como sendo um equilíbrio entre as partes, encontro que no Taoismo ela está relacionada com a busca por um "Realizar-se a si mesmo, em si, e realizar-se a si mesmo no Todo" (Halévy, 2015, 58). Compreendendo o mundo como polaridades, tendo o Yin e o Yang como princípio da impermanência e da mutabilidade, chega-se à ideia de uma atuação cênica em que - INcorporar se dá simultaneamente ao EXcorporar. E, ainda, pensando com Brecht que dois indivíduos formam um coletivo e que, na visão de mundo aqui adotada, "somos todos um", a comunicabilidade se propaga em ondas de pensamento, de acordo com a frequência vibratória de todos que estão no ambiente. Assim, o espectador também participa do ato criador, como processador ativo de um IN e de um EX.

Foi com alegria que li o artigo Energia da presença, a meta principal do treinamento do ator (2015) e agradeço aos pesquisadores Camurri e Zecca $(2015,432)$ que se dedicaram a "verificar a existência de uma Energia da Presença que, por meio de treinamento e ensaio, consiga alterar a propriocepção da pessoa treinada e seu poder de observação". Além de trazerem a confirmação, por experimentos e estatísticas, da Realidade de uma Energia da Presença, apresentam dados fisiológicos importantes para pesquisas afins. Confesso: 1) meu maravilhamento em relação à comprovação dos movimentos de expansão e contração que percorrem o corpo através da conexão crânio-sacral, numa "frequência diferente da do coração e da respiração" (Camurri e Zecca , 2015, 437) o que considero mais uma prova da perfeição do 
Universo; 2) minha anotação, em relação ao treinamento proposto aos artistas que participaram da pesquisa diária, das $6: 30 \mathrm{~h}$ às $23 \mathrm{~h}$, com atividades de treinamento físico, exercícios de propriocepção, kung fu, tai chi e outros, foi "sonho". Isso mesmo. Sonho com uma vida monástica de dedicação a si mesmo, à Arte e em conexão com a sabedoria do Universo.

Confesso, portanto, que me apraz constatar a validação científica (não que esta seja necessária) daquilo que o ator sente/vive em cena e que também tenho visto acontecer em sala de aula, confirmando a propriedade na configuração de um caminho, um percurso artístico-pedagógico, para o qual não prevejo a chegada num lugar determinado. O valor está no próprio caminho - como ensinam diferentes tradições orientais.

Nos últimos projetos de Curso que escrevi, tive dificuldade em redigir os Objetivos. Começou a aparecer uma confusão com o Programa. Pude perceber que o Objetivo é o próprio fazer. O que este fazer vai ou pode gerar é imprevisível e me agrada sobremaneira que seja assim. Quando listamos as unidades de um Programa conectadas à Objetivos a serem alcançados, estamos traçando meras suposições. Não há garantias, não há rede de segurança. Este jogar-se no que ainda não sabemos o que é, torna-se a graça de tudo isso.

Sabemos que em nosso corpo há muitos espaços vazios, assim como muitos líquidos. No Cosmos há mais Energia 3 do que corpos físicos, do que Presença. O Ator pode não ser capaz (ainda?) de criar a Energia cósmica, mas é capaz de ser seu receptor e emissor. Este ator que estou chamado de "iluminado", é aquele que atinge a iluminação em cena.

Imbuída desse sistema de crenças, em contato com disciplinas como: Alinhamento Energético ou Fogo Sagrado, trabalho de origem xamânica, que integra o conhecimento oriental, a Psicologia e a Física Quântica (Mônica Oliveira)4; Leitura Corporal, concebida como a linguagem da emoção inscrita no corpo, conforme Nereida Fontes Vilela ${ }^{5}$; Linguagem orgânica, de Alex Fausti ${ }^{6}$, uma forma de pensar que possibilita ao praticante o reconhecimento de si mesmo, em atitude de completa amorosidade; Yoga du Son, trabalho que vem sendo divulgado no Brasil por Guy Lussier, através de encontros e Oficinas, segundo o qual o canto das vogais, "quando feito com consciência, age sobre a matéria, elevando a frequência vibratória do ser humano, ajustando sua frequência a do planeta, ao mesmo tempo em que acelera a transmutação celular" (Lussie, 2011); Yoga Suksma Vyayama, em que as asanas são feitas seguindo a localização dos Chakras, mobilizando as energias ali localizadas com ressonância em todo o Corpo $^{7}$ - fui levada à elaboração de um caminho artístico-pedagógico, do qual aponto algumas especificidades a seguir.

\footnotetext{
3 Segundo a visão da Leitura Corporal, os corpos que constituem a individualidade (Etérico, Emocional, Mental e Físico) manifestam-se através das várias formas de energia: calorífica, cinética, elétrica, eletromagnética, mecânica, potencial, química, sonora e radiante, expressas em frequência e densidades diversas, e responsáveis por dirigir os processos de experimentação e de desenvolvimento da expressividade. Somos um sistema energético dinâmico, interligado com todo o universo (Vilela e Santos: 2010).

4 Ver: http://www.fogosagrado.net/monica.asp

5 Ver: http://www.leituracorporal.com.br

6 Alex Fausti (1957-2013) - psicoterapeuta com especialização em Terapia Sistêmica Familiar, Cinesiologia Aplicada, Orgonoterapia/Psicoterapia Reichiana, Alinhamento Energético, CranioSacral Therapy, Leitura Corporal, com Extensão em Homeopatia e Neurolinguística.

7 Ver: http://www.yogalotus.com.br/yogasuk-vyayama.htm
} 


\section{A Pedagogia}

A investigação pedagógica teve início como uma disciplina optativa, oferecida aos alunos da Escola de Teatro em 2010, a que chamei de Corpo: o que realmente importa? E ali experimentei a possibilidade de conteúdos referentes aos Chakras e à Leitura Corporal de Nereida Fontes Vilela oferecerem impulsos para diferentes corporeidades, sendo a interrogação uma afirmação da imprevisibilidade dos resultados e da flexibilidade intuída para os procedimentos adotados. As respostas não só corporais dos alunos veio confirmar uma hipótese: a de que um pensamento inteligente, alimentado por conteúdos abstratos que interessam e que tocam a natureza humana do ator podem se converter em corporeidade, cuja concretude no tempo e no espaço e demais propriedades e atributos do Gesto tornam Real o que, aparentemente, é "apenas" Energia, como os Chakras, por exemplo.

Quando o trabalho feito em sala de aula foi para a sala de trabalho no contexto da Pesquisa institucional, com alunos-atores-bolsistas, debruçamo-nos, literalmente, sobre o Guia Visual para Leitura Corporal, elaborado por Nereida Fontes Vilela e equipe. Ali, os componentes emocionais são definidos e apontados em cada segmento do corpo humano, num nível apurado de detalhamento. A tarefa a que nos propusemos foi a de identificar nesses componentes quais os que parecem ter uma conexão direta com os atributos ou necessidades do ator - este que, em cena, está alinhado com o Sagrado.

Cito alguns exemplos:

1) Escápulas - dedicam-se à criação de rumos para a vida pessoal e estruturam as posturas e comportamentos que atendem ao impulso de fazer-se agente da própria história, gerador do novo ou origem das reformas que podem mudar a realidade vivida; 2) Diafragma - adéqua os impulsos genuínos ao processo de sociabilização, sendo a base diafragmática direita responsável por impulsionar o direito à expressão do autêntico e a base diafragmática esquerda, por ativar o direito de recusa à imposição da vontade externa; 3) Abdômen - adéqua os sentimentos, emoções e impulsos naturais da condição humana à vibração própria do indivíduo; 4) Faixa muscular correspondente às vértebras torácicas 12, $11 \mathrm{e}$ 10 - mobiliza os impulsos que sustentam a prática da expressão, a manifestação da força de presença e dos dotes pessoais; 5) Vértebra lombar 1 - ativa e orienta a prática da flexibilidade comportamental e da versatilidade. Equilibra os impulsos de preservação, contenção e liberação, de apego e desapego; 6) Vértebra lombar 2 - estrutura as posturas utilizadas no exercício da autoridade e nas relações de hierarquia, e atua na composição do como exercer a própria competência, reconhecer a competência do outro, comandar ou atender a comandos; 7) Vértebra lombar 4 - atua na estruturação da maneira de alcançar e viver o estado de serenidade e compõe as posturas e comportamentos que trazem tranquilidade nos momentos de decisão. Regula a prática da perseverança e da determinação. (Vilela, s/d)

A leitura das potencialidades que podem ser ativadas pela mobilização ou manipulação das partes do corpo aqui listadas, e que são apenas alguns exemplos, oferece aspectos do perfil desse ator "iluminado" e também o quanto a Leitura Corporal, denominada por sua criadora como "a linguagem da emoção inscrita no corpo" (não há como não se pensar em Artaud) oferece um material de trabalho e de investigação rico e precioso. 
Associamos estes conteúdos com a realização dos movimentos da Suksma Vyayama Yoga, que têm como foco cada um dos sete Chakras básicos, e ainda a conhecimentos advindos da Linguagem Orgânica e chegamos a um aquecimento psicofísico para o ator que consideramos como uma base, composto por:

1) Massagem na face plantar dos pés no ponto correspondente às glândulas suprarrenais, responsáveis pela ativação do estado de presença;

2) Batidas firmes com as pontas dos dedos sobre o osso esterno, considerado o Osso da Comunicação e sob o qual se encontra o Timo, glândula endócrina que tem, entre suas funções, "garantir a consciência da identidade e, no exercício dessa exclusividade e senso de unidade, promover a liberdade para a experiência da totalidade" (Vilela, 2010:94);

3) Massagem nos terços laterais direito e esquerdo da testa, que correspondem e dão acesso à espontaneidade assertiva e afetiva. Segundo a Linguagem Orgânica, assertividade é uma ação realizada com disposição, objetividade, intencionalidade; espontaneidade está ligada à originalidade. Assim, espontaneidade assertiva é quando a Pessoa (o Self) consegue colocar-se com intenção e clareza na direção do intento, num estado de disponibilidade para a experimentação, independentemente do resultado;

4) Prática dos mantras correspondentes a cada Chakra, facilitando a consciência de sua força e das partes do Corpo Físico que são suas áreas de projeção, o seu alinhamento e funcionamento equilibrado, ampliando a percepção do corpo para além do próprio Corpo Físico, já que os Chakras se localizam, efetivamente, no Corpo Etérico;

5) Execução dos movimentos da Suksma Vyayama Yoga, associando as áreas do corpo que se movem com a "linguagem da emoção" ali circunscrita. Exemplos: ao realizar o movimento de elevar e abaixar os braços lateralmente, perceber a participação das escápulas, com a consciência de estar entrando em contato com questões relativas à autonomia; nos movimentos da nuca, a consciência de que cada uma das sete vértebras cervicais representam os sete Chakras básicos que, assim, estão sendo ativados;

6) Realização de movimentos com foco nas partes do corpo onde se localizam os Centros, de acordo com as necessidades do ator. Alguns deles são: Centro de Encaminhamento das Emoções e Sentimentos, localizado no diafragma; Centro Estimulador do Poder Criativo ou Centro da Criatividade, na articulação coxofemoral; Centro da Valorização Pessoal, nos joelhos; Centro do Equilíbrio, nos tornozelos. Vilela (2010) identifica cerca de setenta Centros, situados claramente em determinadas áreas de Corpo.

O Corpo Etérico, onde se localizam os Chakras, é um campo energético que consiste numa teia de linhas de força, com a mesma conformação do corpo físico e que preenche tanto o interno quanto o externo do corpo. É percebido a uma distância de dois a três centímetros do corpo, onde é mais denso. No plano sutil, o Corpo Etérico transporta e transmite os impulsos-mensagens, códigos que suscitam e impulsionam a inspiração, o desejo e a vontade - forças geradoras do movimento. No plano material, ele modela, sustenta e anima o Corpo Físico, que é agente da expressão e instrumento para a ação (Vilela e Santos, 2010). Essa definição e as experiências realizadas nos fazem acreditar ser ali que se processa a criação artística, que só se concretiza com a participação de outros três Corpos (Emocional, Mental e Físico). 
Se considerarmos que o impulso é o primeiro suporte para a ação teatral, definindo sua intencionalidade expressiva, se acreditamos na possibilidade de preenchimento do espaço da cena para além da fisicalidade restrita do ator, se acreditamos na correspondência perfeita entre ação interna e externa, o Corpo Etérico é o lugar onde pode se dar um Estado de Consciência de Ator. É este Corpo que se "ilumina" no palco.

\section{A Cena}

A primeira experiência em trazer este trabalho para uma construção cênica, realizada pelos alunos-atores-bolsistas Iniciação Científica (IC) e PIBIC Andrea Rocha Tonia, Douglas Resende de Souza e Renata Santos Sampaio, deu-se com a utilização de minicontos de João Gilberto Noll, publicados no livro Mínimo, múltiplos, comuns (2003). Cada ator selecionou e decorou os minicontos. Cada um, elegeu um "padrinho", protetor, inspirador entre os Guardiões do Fogo Sagrado, conforme o entendimento deles feito pela Linguagem Orgânica de Alex Fausti, e um dos sete Chakras, de onde o impulso, o motor da criação partia. Em algumas sessões de trabalho, eu realizava a Leitura do Campo Energético ${ }^{8}$ de cada um dos atores. Este costuma se dar a ver através de imagens, a partir das quais cada um dos atores iniciava sua composição sobre o conto eleito para aquele dia. Confesso minha dificuldade em fazer uma avaliação do resultado cênico deste trabalho, mostrado publicamente apenas uma vez. Credito essa dificuldade a uma atitude pedagógica deliberada de não trabalhar para um resultado, mas sim, como já afirmado, para a realização de uma jornada, um percurso. Uma das atrizes, Andréa Tonia, afirmou em relatório que "o que se pretende com a prática pesquisada é uma atitude do artista que o coloque em integridade consigo próprio e com o trabalho que realiza, para que a cena seja um espaço de pulsações potentes numa mesma frequência, sempre no intuito de estabelecer conexões e compartilhamentos." É isso.

Confesso aqui outra dificuldade, uma impossibilidade, talvez, em propor aos alunos-atores o que eu não tenha experimentado. Durante o período em que trabaIhava com a prática narrativa, eu podia compreender o que se passava com eles por ter realizado, eu mesma, um longo treinamento e espetáculos na estética do teatro rapsódico. Quando a espiritualidade invadiu a sala de trabalho, as propostas que eu fazia aos alunos-atores eram novas para mim. Precisava experimentá-las, e foi o que fiz. Depois de cerca de dois anos, precisei viver a experiência de levar à cena o que estava acontecendo comigo. Nas palavras de Andréa Tonia, já citadas, no intuito assumido de "estabelecer conexões e compartilhamentos", em várias esferas".

Encenei No se puede vivir sin $\operatorname{amor}^{10}$, com textos do meu amigo Caio Fernando Abreu, sobre o que já tive oportunidade de realizar Palestras-demonstração, em que tenho revelado o processo de criação, e também exposto a sua desmontagem ${ }^{11}$.

\footnotetext{
8 Trata-se da primeira etapa do Alinhamento Energético, Fogo Sagrado, em que o terapeuta tem acesso às imagens presentes no campo de energia do paciente. Em geral, referem-se às questões que precisam ser tratadas no momento.

9 Escrevi um desabafo sobre o assunto, publicado em: http://redeglobo.globo.com/globoteatro/artigos/noticia/2015/02/nara-keiserman-falta-de-pudor-esta-emcena.html

10 A peça estreou em Belo Horizonte, 2013. Foi apresentada no $28^{\circ}$ Festivale - Festival de Teatro de São José dos Campos; em 2015 cumpriu temporada, no Rio de Janeiro, no Espaço Sesc, no Teatro Cândido Mendes e no Espaço Tom Jobim. Foi apresentado, ainda em 2015 no Festival de Inverno de Ouro Preto e Mariana - Ouro Preto, e no Festival Aldeia Velho Chico - Sesc Petrolina.

11 Desmontagem: partilhamento escancarado de performances solo. Mesa temática. Jacyan Castilho, Mara Leal e Nara Keiserman. VIII Congresso Abrace, 2014.
} 
Recentemente, afirmei que ainda não poderia dizer que faço um teatro espiritual, porque meus temas são profanos, mundanos, humanos. Mas que considerava fazer/ propor uma prática teatral da espiritualidade, porque com ela, a prática, pretendia favorecer a expansão dos limites do profano, do mundano, do humano. Hoje, começo a achar que sim, o que faço em cena pode ser chamado de teatro espiritual.

O que segue é o que ainda não revelei e só o faço agora por um amadurecimento do trabalho em mim, uma certeza e confiança no encaminhamento artístico -pedagógico que me propus a trilhar.

No camarim, arrumo meticulosamente minha bancada. Toalha "indiana", a imagem de Ganesha e de um "buda" risonho, incenso. Faço minha maquiagem ouvindo Gurumayi Chidvilasananda ${ }^{12}$ cantando um Mantra em honra a Muktananda, seu Guru $^{13}$. Já pronta, canto a oração Jyota se jyota, em que se evoca o Guru para que ele acenda nossa chama com a sua chama.

No palco, disponho os objetos ritualísticos na mesa que compõe o cenário: toalha branca, cristais, outro "buda" risonho, um elefante, jarra com água e copo brancos, o baralho dos Guardiões do Fogo Sagrado. Andando por todo o espaço, cena e plateia, evoco o Guardião Velho Jardineiro, para a limpeza do ambiente e Bianashura, também Guardiã do Fogo Sagrado, que tem correspondência com a deusa indiana Laksmi, as duas relacionadas à fortuna e abundância. Faço a peça toda, percorrendo os espaços, pronunciando o texto mentalmente e cantando as canções da peça, que incluem corimbas dedicados à Jurema, Oxum e lemanjá. Cantá-los é o que me possibilita colocar-me no estado que gosto e preciso para a cena que está por vir. Faço um exercício corporal para o equilíbrio dos meridianos, canto o mantra dos Chakras.

Já na presença dos espectadores, faço mentalmente uma oração, em que agradeço à Força Cósmica do Amor Universal e a outras forças de Luz por estar ali, pisando em solo sagrado. Pressiono pontos específicos do corpo, conforme a Leitura Corporal: o ponto na face plantar dos pés que corresponde às glândulas suprarrenais e ativam a Presença; os joelhos, intencionando um equilíbrio nos valores interpessoais, na certeza de que os espaços da cena e dos espectadores têm o mesmo valor; o esterno, para que a comunicação se estabeleça efetivamente e uma rede de conexões amorosas se forme entre todos os presentes; os terços laterais direito e esquerdo da testa, para as espontaneidades, de modo a assegurar minha inteligência cênica para o trabalho; a vértebra cervical denominada atlas, intencionando que eu possa estabelecer uma conexão com os espectadores, com o autor do texto, com o universo ali presente. Dirijo-me para a mesa, embaralho as cartas dos Guardiões do Fogo Sagrado, evocando a bênção de um deles para guiar o acontecimento teatral que vai ser vivido por todos naquele momento. Tiro uma carta "ao acaso" (na verdade é o Guardião que se oferece) e partilho com os espectadores o nome, a imagem e a função básica do Guardião. E canto:

"O compositor me disse que eu cantasse distraidamente essa canção / Que eu cantasse como se o vento soprasse pela boca vindo dos pulmões / e que eu ficasse ao lado pra escutar o vento jogando as palavras pelo ar."

12 Guru viva da linhagem da Siddha Yoga. Ver: http://www.siddhayoga.org

13 Ver http://www.siddhayoga.org/baba-muktananda 
Aprendi com minha professora de canto, Alba Lírio, que a voz segue o sopro e a mente segue a voz. Gilberto Gil, na canção acima citada, diz a mesma coisa. É o que tenho procurado: respirar e deixar que a energia vital, o prana, escoe pelos meus nadis para o espaço sagrado da cena.

\section{Referências}

CAMURRI, Nicola e ZECCA, Christian. Energia da presença, a meta principal do treinamento do ator. Revista Brasileira de Estudos da Presença, Porto Alegre, v.5, n.2, p.431-457, maio-agosto 2015.

DIÉGUEZ, Ileana. Des/tejiendo escenas. Desmontajes: procesos de investigación y creación. (Compilação). México: Universidad Iberoamericana Ciudad de México, 2009.

HALÉVY, Marc. Leitura do Tao. São Paulo: Vozes, 2015.

LUSSIER, Guy. Yoga du son. O canto das vogais. Apostila de Oficina, 2011.

NOGUEIRA, Roberto. Yoga Suksma Viayama. Desenvolvimento do vigor corporal. Apostila, 2006.

OLIVEIRA, Mônica e TUI, Letícia. Fogo Sagrado. Alinhamento Energético. Apostila do Curso Básico de Formação, 2009.

MUKTANANDA, Swami. O Jogo da Consciência. Rio de Janeiro: Siddha Yoga Dahm Brasil, 2000.

VILELA, Nereida Fontes e SANTOS, João Celso dos. Leitura corporal. A linguagem da emoção inscrita no corpo. Belo Horizonte: Núcleo de Terapia Corporal, 2010.

VILELA, Nereida Fontes e outros. Guia Visual para Leitura Corporal. Belo Horizonte: Núcleo de Terapia Corporal, s/d.

NOLL, João Gilberto. Mínimos, múltiplo, comuns. São Paulo: Francis, 2003.

Recebido em: 30/09/2015

Aprovado em: 25/02/2016 